Journal of Educational

Technology \& Online Learning

Volume 4 | Issue 4 | 2021

http://dergipark.org.tr/jetol

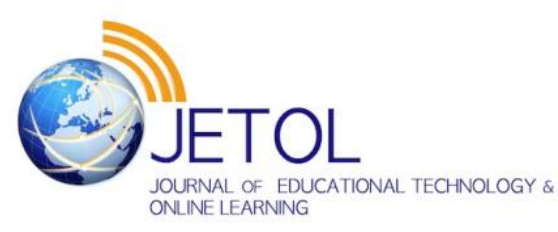

\title{
Video feedback via QR codes for pre-service English teachers
}

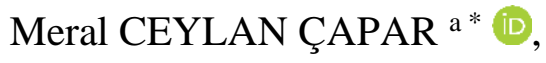 \\ a Anadolu University, Turkey
}

Suggested citation: Ceylan Çapar, M. (2021). Video feedback via QR codes for pre-service English teachers. Journal of Educational Technology \& Online Learning, 4(4), 605-625.

\begin{tabular}{ll}
\hline Article Info & Abstract \\
\cline { 2 - 3 } $\begin{array}{l}\text { Keywords: } \\
\text { Video Feedback }\end{array}$ & $\begin{array}{l}\text { QR Codes have been flourishing the education for many long with the variety of } \\
\text { activities in use it provides, and have been preferred especially for being simple and } \\
\text { Online learning } \\
\text { Preservice English teachers } \\
\text { Academic writing }\end{array} \quad \begin{array}{l}\text { the learners for qualified essays. The aim of this qualitative study is to find out the } \\
\text { experiences of preservice English teachers on video feedback via QR codes. 50 } \\
\text { preservice teachers were asked to write two essays. At the end of the term, data were } \\
\text { collected via an open-ended questionnaire and semi-structured interviews. 23 of the } \\
\text { candidates completed the open-ended questionnaire and } 8 \text { of them accepted to be } \\
\text { interviewed. Data were analyzed through thematic coding. It was expected that the } \\
\text { participants would develop positive attitudes towards video feedback, yet the findings } \\
\text { showed they prefer written feedback on their word files and felt safer that way. This } \\
\text { study may contribute to the field in terms of how to develop ways to provide more } \\
\text { efficient feedback for preservice teachers and may show that affective factors have also } \\
\text { key roles in the success of certain methods and approaches in teaching. }\end{array}$ \\
\hline
\end{tabular}

\section{Introduction}

Feedback has an important role in language learning, especially for online language courses (Atwater et Al., 2017; Belt \& Lowenthal, 2021; Borup et al., 2015). Via video feedback, learners can have the opportunity to improve themselves (Donkin et al., 2019). Since the learners have limited opportunities to meet their instructors face-to-face, instructors providing more frequent and detailed feedback becomes a necessity because it can be seen as a way to prevent the feeling of isolation in online learning (Goldingay \& Land, 2014; Yuan \& Kim, 2014). Moreover, the instructors can promote their learners' satisfaction, learning and motivation by providing feedback (Garrison, 2009; Li et al., 2020; Thoms, 2011). Hyland and Hyland (2006) claim that feedback is regarded as a vital developmental tool in process-oriented and learnercentered classrooms because it provides learners to move through multiple drafts to effective selfexpression. Therefore, according to the feedback students receive, they can be aware of what they have learned and what they need for further improvement in language learning. Especially, in teaching writing (Hyland \& Hyland, 2019; Yu et. al, 2018), with the process-oriented approach, feedback has become more important. Since students produce many drafts before the final product, they receive feedback on each draft, so by revising the drafts using the feedback, they learn how to express their ideas through writing.

Feedback can focus on both global (content, organization, and so forth) and local issues (grammar, mechanics, and so forth) (Sheen \& Ellis, 2011). Although Truscott (2007) claims that grammar correction

\footnotetext{
* Corresponding author: ELT Department, Education Faculty, Anadolu University, Turkey.

e-mail address: meralceylan@anadolu.edu.tr

This study was partly presented as a proceeding at the 1st International Conference on Educational Technology and Online Learning Conference held between 22-24 September 2021.
} 
does not lead to an improvement in student writing development, many teachers prefer giving feedback on grammar. As a result, the students only see grammar corrections on their papers. Bould and Molloy (2013) claim that the aim of feedback should not only be the correction of grammar and weak points in the written text but also create a positive impact on what learners can do. These views about feedback may lead us to the belief that feedback is a "communicative act" in fact (Ajjawi \& Boud, 2018, 3). While providing oral (face-to-face) feedback to learners, they have the chance to interact. They can focus on both global and local level problems in the text, the learners can ask further questions, and so on. However, this may not be the case for online courses. Thus, video feedback provides learners the opportunity to interact with their instructors and gives the instructors the chance to talk about more details about the learner text unlike written and audio feedback (Mahoney et al., 2019). Researchers and educators have focused on written and audio feedback quite in detail (Dowden et al., 2013; Gould \& Day, 2013; Jolly \& Boud, 2013; Vardi, 2013); nevertheless, video feedback has received less attention especially with English Language Teaching preservice teachers. Consequently, the aim of this study is to investigate ELT preservice teachers' experiences on video feedback via QR codes they received on their essays.

\section{Literature}

Feedback has a significant role in the learning process no matter what the field is. For especially preservice ELT teachers, it is of the most importance because they need to be good and effective writers and teachers and provide feedback to their future learners. In other words, providing ELT preservice teachers with effective feedback will also teach them how to give feedback to their future learners and calling this as "butterfly effect" would not be wrong.

\section{Feedback}

Feedback on students' papers is categorized into two groups: global and local feedback. Global feedback focuses on content and organization development, and local feedback focuses more on form, such as grammar and mechanics. When teaching writing, it is believed that paying attention to both global and local levels is essential. The focus of this study is both. Since students are learning a new language, they constantly need feedback to improve the language both in speaking and writing skills for both at the global and local level (Ferris, 2004). Hsieh and Hill (2021) found in their study that instructors pay more attention to academic writing style, comment on tone and word choices besides language-related errors (Waller \& Papi, 2017). According to them, instructor feedback in language learning and writing can be seen as an aid for language learning and in developing writing skills (Ellis, 2006; Ferris \& Roberts, 2001).

Providing feedback for learners can encourage them to learn more and trigger their enthusiasm for it. It is significant to remember that without short-term gains long-term gains cannot be achieved (Ferris, 2002), and Ferris adds that students expect error correction on their papers and providing what they expect can motivate them in writing. When learners receive feedback, they feel important and struggle more to develop their language and writing skills (Kormos, 2012; Ruegg, 2018; Wright et al., 2019). While learners require feedback for their work and feel enthusiastic for it, for the teachers, providing feedback to language learners needs time and a lot of effort. Hyland and Hyland (2006) state that although teachers are reluctant to give feedback, they think that they should provide feedback according to the students' needs. Besides, as the study of Chen (2019) suggests language learners become more interactive when the teacher is involved in their learning process. Providing feedback and discussing it is one way to support this interactive learning process.

The importance of providing feedback cannot be denied according to the literature; however, what matters now, in the current era, is the means the feedback is delivered. Surely, what the learners benefit most is oral feedback, the feedback they receive face-to-face, but the developing technology and the changing profile of learners-namely, digital learners-encourage teachers to find more effective and motivating ways to provide feedback for their digital learners, especially during the pandemic which COVID-19 has caused. 
Alternatives for face-to-face feedback should be found to support the learners, such as, written feedback, audio feedback or video feedback.

\section{Written Feedback}

Written feedback usually means corrective feedback. The teacher provides feedback on the margins of the text, underlines the parts which need revision, and so on. Feedback focuses mainly on the language use, content development, and/or the organization of the ideas. The literature at issue puts forward that written feedback has a highly positive effect on the text quality (Bitchner \& Knoch, 2009; Bonilla López et al., 2018; Van Beuningen et al., 2012). This type of feedback can be considered the basis for audio and video feedback. In other words, audio and video feedback are based on written feedback. During the pandemic/lockdown, the teachers and learners had to decide how the feedback should be delivered: sending the written feedback via word file or similar, or in audio form or video form.

\section{Audio Feedback}

Audio feedback is the recorded feedback that the instructor provides for the learner. This type of feedback comprises the comments of the teacher and can be an opportunity to cover the points that written feedback may lack (Kostka \& Maliborska, 2016) since the teacher will have more room to explain their point of view. Moreover, there are some studies which show that learners may pay more attention to audio feedback (Cavanaugh \& Song, 2014; Ice et al., 2007). Wood et. al. (2014) echo this statement by emphasizing that since audio feedback is a way to construct interaction with the learners, learners may feel important, cared, and eventually, they get more motivated. Also, Ahern-Dodson and Reisinger (2017) found that foreign language learners in their study favored feedback which was presented in written and audio form because it was more "thought-provoking" (p.138). Audio feedback can be delivered in form of MP3 files, software programs, such as Turnitin, and so on.

\section{Video Feedback}

Video feedback can also be referred to as screencast feedback by some experts such as Mathisen (2012), Thompson and Lee (2012), and Turner and West (2013). Screencast feedback can be explained as the recording that the teacher makes from his/her computer screen and shows the mouse movements, scrolling and typing, and provides audio feedback (Henderson \& Phillips, 2014).

Although written feedback is the basis for video feedback, video feedback gives the learners the chance to receive more detailed feedback (Mayhew, 2017; Vincelette \& Bostic, 2013). The study of Moore and Filling (2012) supports this view with the findings of their study. They found that while providing video feedback, teachers were giving more detailed suggestions, tried to make comments on language use and elaborated the important points and details. Moreover, in other studies, it was found that video feedback encouraged the teachers to focus more on positive aspects of the learner texts (Lamey, 2015; Thomas et. al., 2017). Henderson and Phillips (2015) claim that video feedback may lead teachers to focus less on surface-level mechanics of writing and more on global aspects of the texts (Lamey, 2015; Orlando, 2016). Thus, video feedback encourages teachers to provide more feedback on content development, organizational problems, unity, and coherence. The aforementioned studies also found that students work on global issues of their texts more when they receive video feedback.

Furthermore, video feedback can be a means for constructing interaction with the learners. Since the teacher greets the students at the beginning of the video and says 'bye' at the end, and perhaps addresses the students by name during the video, the learners perceive the video feedback as more conversational (Anson et. al., 2016; Grigoryan, 2017). Anson et. al. (2016) found in their studies that video feedback could be a means for face-to-face interaction and may improve the relationship between the teacher and the learner. The study 
of Meşe and Sevilen (2020) revealed that L2 learners had negative attitudes towards online learning because of lack of social interaction. Video feedback can be a means to support social interaction with the learners.

Since the advantages of video feedback overweigh the ones of audio feedback when the literature is considered, in this study, video feedback was preferred as a means to provide feedback for preservice ELT teachers. Also, studies on feedback have mainly focused on language learners rather than ELT teacher candidates (Dowden et al., 2013; Ellis, 2006; Ferris \& Roberts,2001; Gould \& Day, 2013; Ene \& Upton, 2018; Jolly \& Boud, 2013; Ruegg, 2018; Vardi, 2013; Waller \& Papi, 2017). Nonetheless, it is obvious that every method applied with teacher candidates does not only develop their English writing skills but also may contribute to their teaching skills. This is based on the belief that any experience with preservice teachers contributes to their teaching skills and this may create a "butterfly effect". Accordingly, this study focuses on the opinions of ELT teacher candidates on video feedback in their writing skills course. Thus, it is believed that this study can contribute to the literature and the field of ELT in terms of developing ELT preservice teachers' academic writing skills and teaching skills. Regarding this aim, the research question of the study is:

1. What type of feedback do preservice English teachers prefer while having an online writing skills course?

a. What are the reasons for their preferences?

\section{Methodology}

\subsection{Research Model/Design}

In this study, qualitative research, more specifically, phenomenological study design was used. Phenomenological research is based on the experiences reported by the individuals which allow us the opportunity to see the perspectives of the subjects (Creswell, 2005). Since the aim of the study was to find out the experiences and opinions of the ELT preservice teachers on video feedback, the phenomenological study design was found to be the most suitable design to be applied. In other words, this study is concerned with describing the participants' experiences rather than explaining them, and gaining insights in the preservice teachers' motivation and actions in receiving video feedback for their essays.

The study was conducted in a "writing skills II" course at the ELT department of an education faculty in Turkey. The course focuses on academic writing and the syllabus comprises some basic types of essays. Since the pandemic suddenly hit the education system in a sudden way, the syllabus was revised and two types of essays were taught online to preservice teachers: cause-effect essay and argumentation essay.

The course applies process approach for homework where the preservice teachers receive feedback on their essays and then, they are required to revise their essays according to the feedback they receive from their instructors. For the cause-effect essay, the preservice teachers received feedback on the word file they submitted to the LMS (Learning Management System) the university was using. For the argumentation essay, they were provided with video feedback which they could reach via a QR (Quick Response) code sent to their emails (Figure 1). 


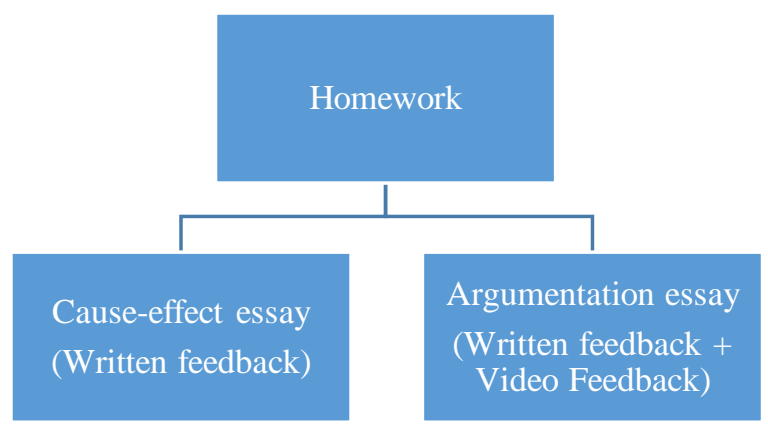

Fig. 1: Type of feedback according to the essay type

\subsection{Study Group}

The participants of the study were 50 ELT preservice teachers attending the 'writing skills II' course in the spring term of the academic year of 2019-2020 They were freshman students whose ages ranged from 18 to20. The feedback for two essay types was provided in written-only and video +written format for all 50 participants. Although 20 participants completed the survey, 3 participants were not able to complete the survey due to health and technological problems. 8 of the participants agreed to be interviewed. The rest of the participants did not complete the survey although they received feedback during the term. All preservice teachers were provided with feedback during the term, but they participated in answering the survey and the interview on a voluntary basis.

\subsection{Data Collecting Tools}

\section{Video Feedback and QR code}

The participants received feedback for the cause-effect essay in written format in the word file they uploaded on the LMS. The word files were sent one by one to each participant's mailbox. For their argumentation essay, they received feedback both in written form and video format. At this point, since the size of videos was big and could not be sent via email, QR codes were used by sending the participants the codes they had to use to access their feedback. Another reason why QR codes were preferred was the application called "Qwiqr" (https://uk.qwiqr.education/). This application offers the easiness to record the video on the application directly and creates QR codes for it; in other words, it also saves time. On the recording, the participants could see their written feedback, and they could also listen to their instructor explaining both the strong and weak sides of the essay by showing them on the screen with the mouse and 
by highlighting the necessary parts (see Picture1). Thus, the participants could read the comments of the instructor, listen to the feedback, and see the relevant parts.

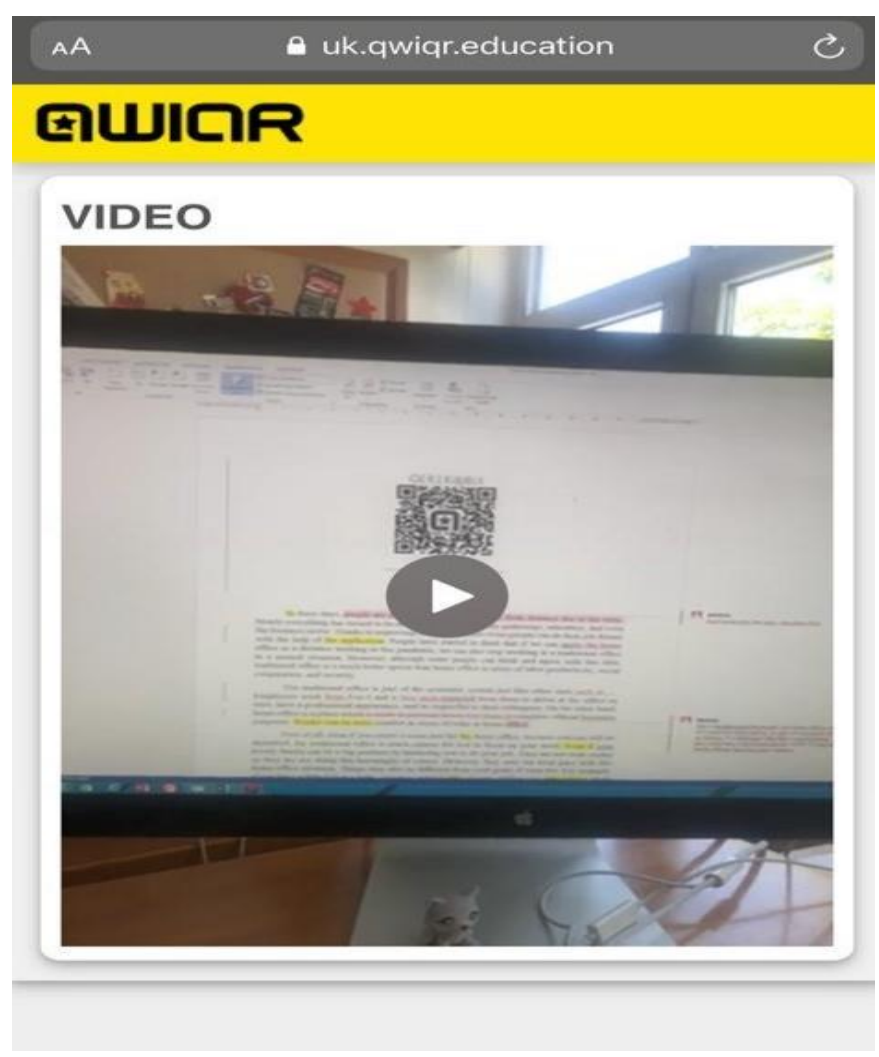

Pic.1: Qwiqr Screen

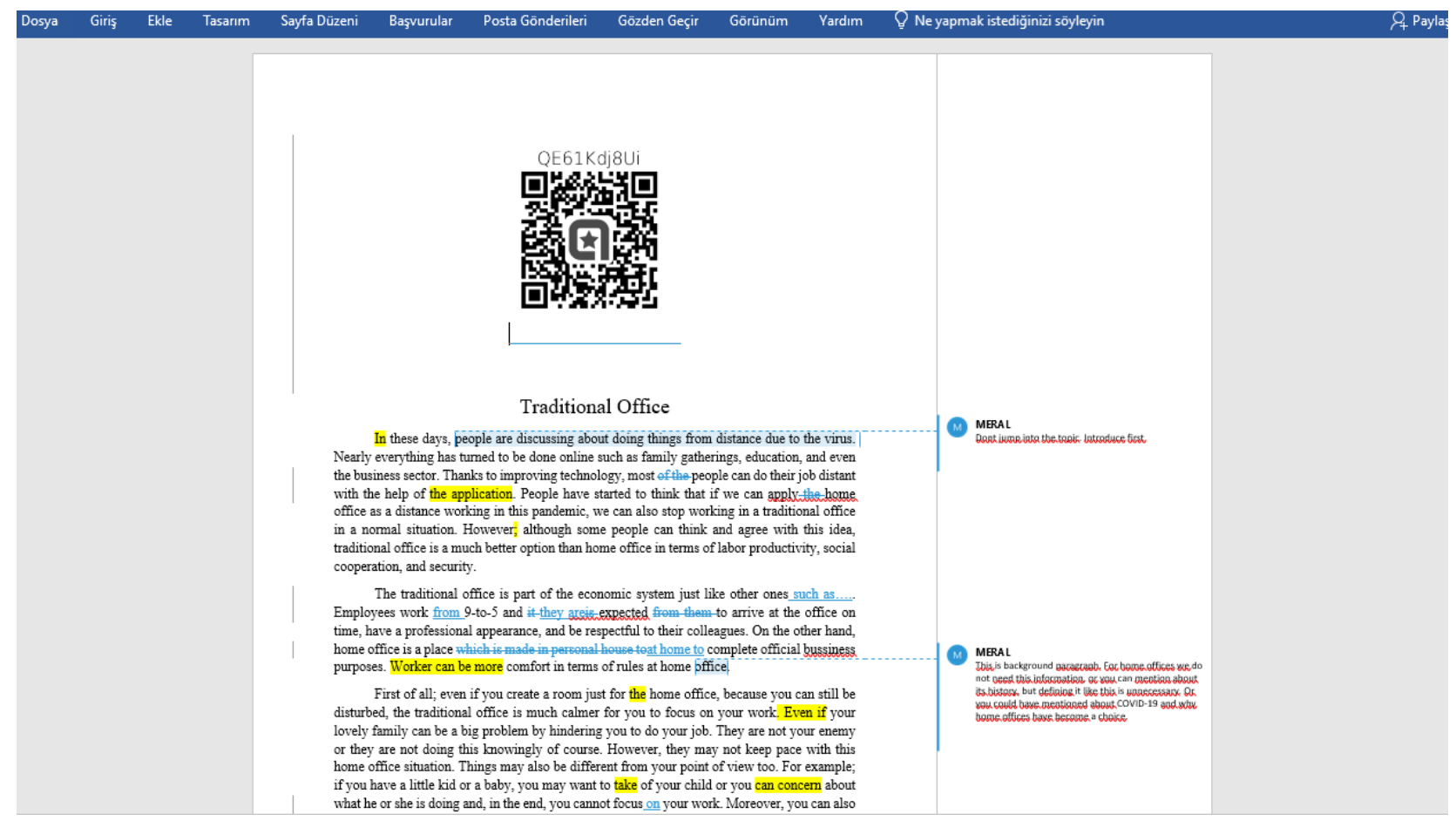

Pic.2: Student sample video feedback via QR code 


\section{Open-ended Survey}

An open-ended questionnaire was prepared online for the participants. The questions consist of three parts: demographic information, 8 experience-related questions and consent for the use of their answers for academic purposes. Before the questionnaire was applied to the participants, two field-related experts examined the questionnaire and provided feedback both for the format of the questionnaire and the wording of the questions so that they would be clear enough for the participants. 5 of the participants who were excluded from the main study answered the survey beforehand in terms of checking the difficulty of the questions, and the problematic ones were revised accordingly. Thus, based on the critics of the experts and the five participants, revisions were made.

\section{Semi-structured Interview}

Two questions related to the experiences of the participants were prepared. During the interview, when the necessity for further questions arose, follow-up questions were asked to the participants too. The interviews were conducted with eight volunteer participants. The two questions were as:

1. Which feedback type do you prefer? Written or video feedback? Why?

2. Why wouldn't you prefer the other one?

The interviews were carried out on Zoom and they were recorded with the permission of the participants. The interviews were transcribed verbatim for detailed content analysis. Figure 2 shows the data collections tools used for the study.

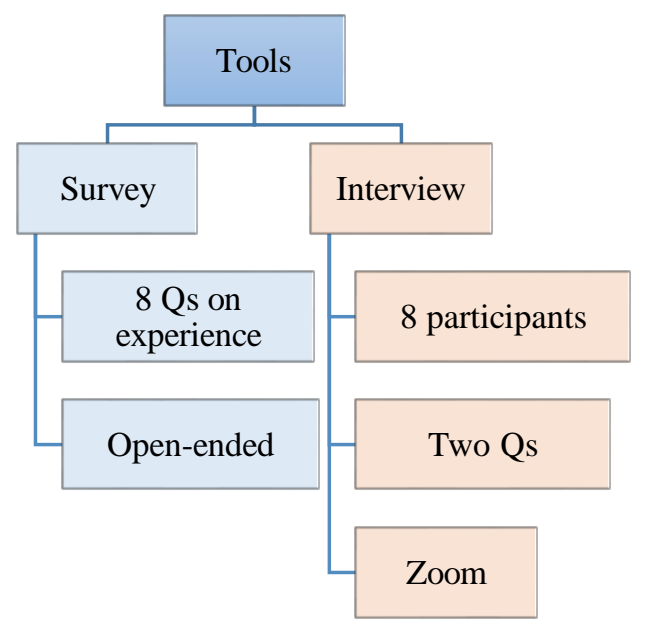

Fig. 2: Data Collection Tools

\subsection{Application Process}

The aim of the study was to explore the experiences of ELT preservice teachers on video feedback during the online writing course during the lockdown. The preservice teachers were expected to write two essays as homework in the spring term. The homework was assigned to the participants after they were taught each essay type. Hence, the first essay type was the cause-effect essay and the second was argumentation essay (as presented in Figure 1).

The participants received written feedback only for their first homework on a word document. The feedback was provided within the text by correcting mechanical errors and with margin notes which would help them 
to improve their texts in terms of content, organization, unity, and coherence. The documents with the feedback were uploaded to the LMS.

After the argumentation essay was taught, the second homework was assigned. This time, the participants were provided with written feedback and video feedback. Mechanical errors were mentioned in written feedback. If they were very frequent and of a specific type, then they were explained in the video. Margin notes were used again for content and organization development, but this time video feedback supported those notes. In the video feedback, the problematic part was shown exactly to the participant and necessary information was provided on how to solve the problem and develop their text. The video feedback was recorded via the web tool Qwiqr" (https://uk.qwiqr.education/). QR codes were preferred because sending the video recording would be difficult in terms of size, so this application assisted in sharing the feedback with the participants in a practical way. The files with written feedback and QR codes for the video feedback were planned to be uploaded on the LMS; however, there was a technical problem and the upload failed, so the instructor had to send the files to each student via email.

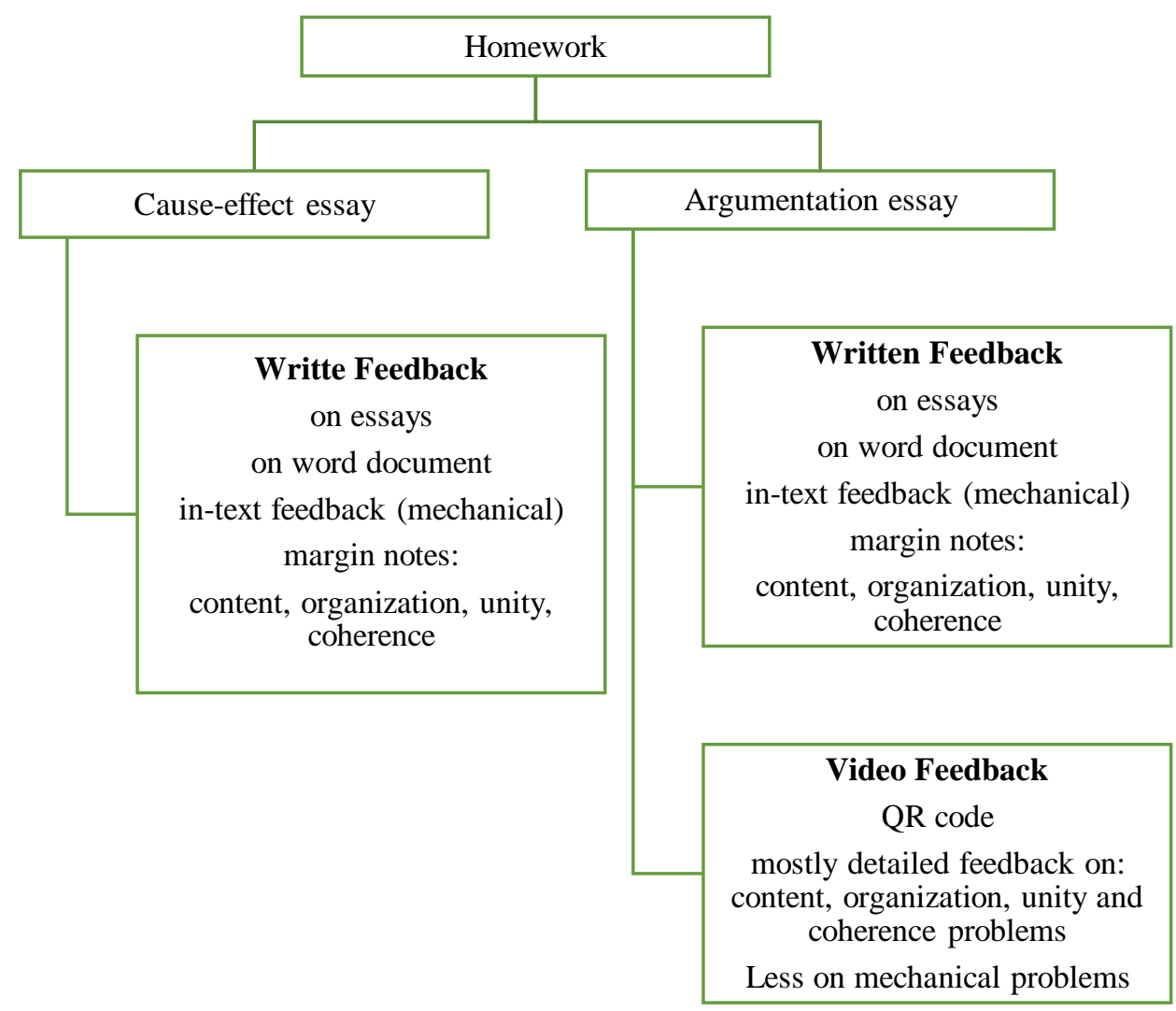

Figure 3. Application Process

At the end of the term, after the final exams, the participants were asked to complete the open-ended survey for the study and to consent for their participation in the data collection process. After the survey, volunteer participants were interviewed on their experiences of receiving feedback and how this improved their essays. 


\subsection{Data Analysis}

Qualitative data analysis was used for both the survey data and interview data sets. More specifically, content analysis was carried out. The interviews were transcribed verbatim. For both data sets, theme coding was applied on NVivo12. Two experts applied theme coding to the data sets, and a third expert was consulted for the parts where consensus was needed.

\subsection{Validity and Reliability}

For coding reliability, two coders identified the themes in the data. At the first stage, after $30 \%$ of the data were coded by the coders, for the themes which could not be agreed on, a third expert was consulted. The whole data were analyzed by two experts; then, the reliability Kappa coefficient was found on NVivo12 as 0.83 , which can be considered as highly reliable. Figure 4 shows the procedure for data analysis and reliability.

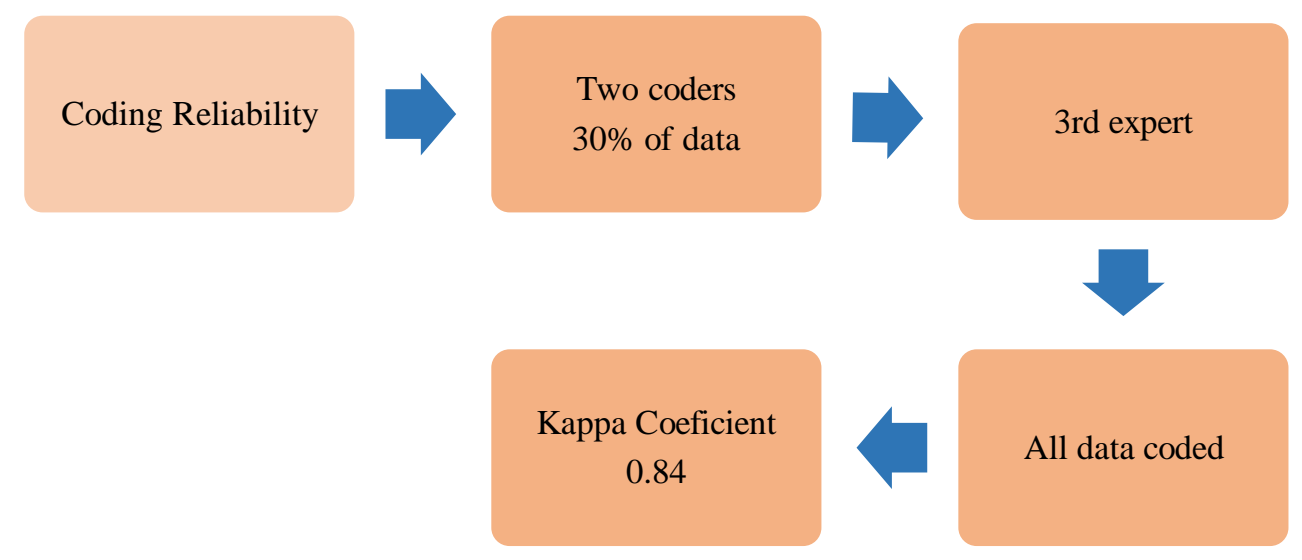

Fig. 4: Data Analysis Procedure

\subsection{Findings and Discussions}

The aim of the study is related to the preferences and opinions of the pre-service teachers. They were asked which feedback type they preferred: written-only feedback or video feedback +written feedback. While $60 \%$ of the participants preferred video feedback and written feedback, $40 \%$ of the participants preferred written-only feedback.

When the reason for their preferences was asked, the participants stated that receiving video feedback during the pandemic made them feel cared and important because they thought it was a sign that the instructor cared about them. Also, they added that more detail was provided via video feedback. On the other hand, the participants who preferred written feedback stated the reason for their choices as they were not good at using technological devices and found it time-consuming to download a QR scanning application and then to watch the video. They preferred written feedback because it was more straightforward for them. 


\section{Table 1.}

Preference of Feedback Type

\begin{tabular}{lll}
\hline Type of Feedback & Percentage & Reasons \\
\hline Written-only feedback & $40 \%$ & $\begin{array}{l}\text { Straight forward } \\
\text { Practical } \\
\text { Traditional }\end{array}$ \\
& & More detailed \\
Video Feedback+Written & $60 \%$ & Felt more cared \\
feedback & & Visual and audio feedback \\
& & \\
\end{tabular}

Considering this finding, the study went through a more detailed analysis of their preferences and experiences about video feedback+written feedback and written-only feedback. The participants were asked which type of feedback they found effective (Table 2). When they were asked about their opinions on the effectiveness of video feedback+written feedback and only written feedback, $48 \%$ of the participants found video feedback more effective whereas $52 \%$ found written feedback only more effective. This finding may seem contradictory because while most of the participants preferred video feedback + written feedback, they found the one with video feedback less effective (Table 2).

Table 2.

Type of feedback preference and its effectiveness

\begin{tabular}{lll}
\hline & $\begin{array}{l}\text { Preference } \\
\text { (Percentage) }\end{array}$ & $\begin{array}{l}\text { Effectiveness } \\
\text { (Percentage) }\end{array}$ \\
\hline Written-only feedback & $40 \%$ & $52 \%$ \\
Video Feedback+Written feedback & $60 \%$ & $48 \%$ \\
\hline
\end{tabular}

\section{Reasons for Preferring Written-only Feedback type}

The participants uploaded their cause-effect essays on a word file on the LMS of the university. On the file, the instructor corrected the language use, suggested more complex vocabulary and grammar structures, and wrote suggestions on the margins as comments about the content and organization of the essays. The files were sent via email to the participants.

When participants stated their preference as written-only feedback, the reasons for their choices were found out. Figure 4 presents the reasons why written-only feedback was preferred over video feedback+written feedback. 


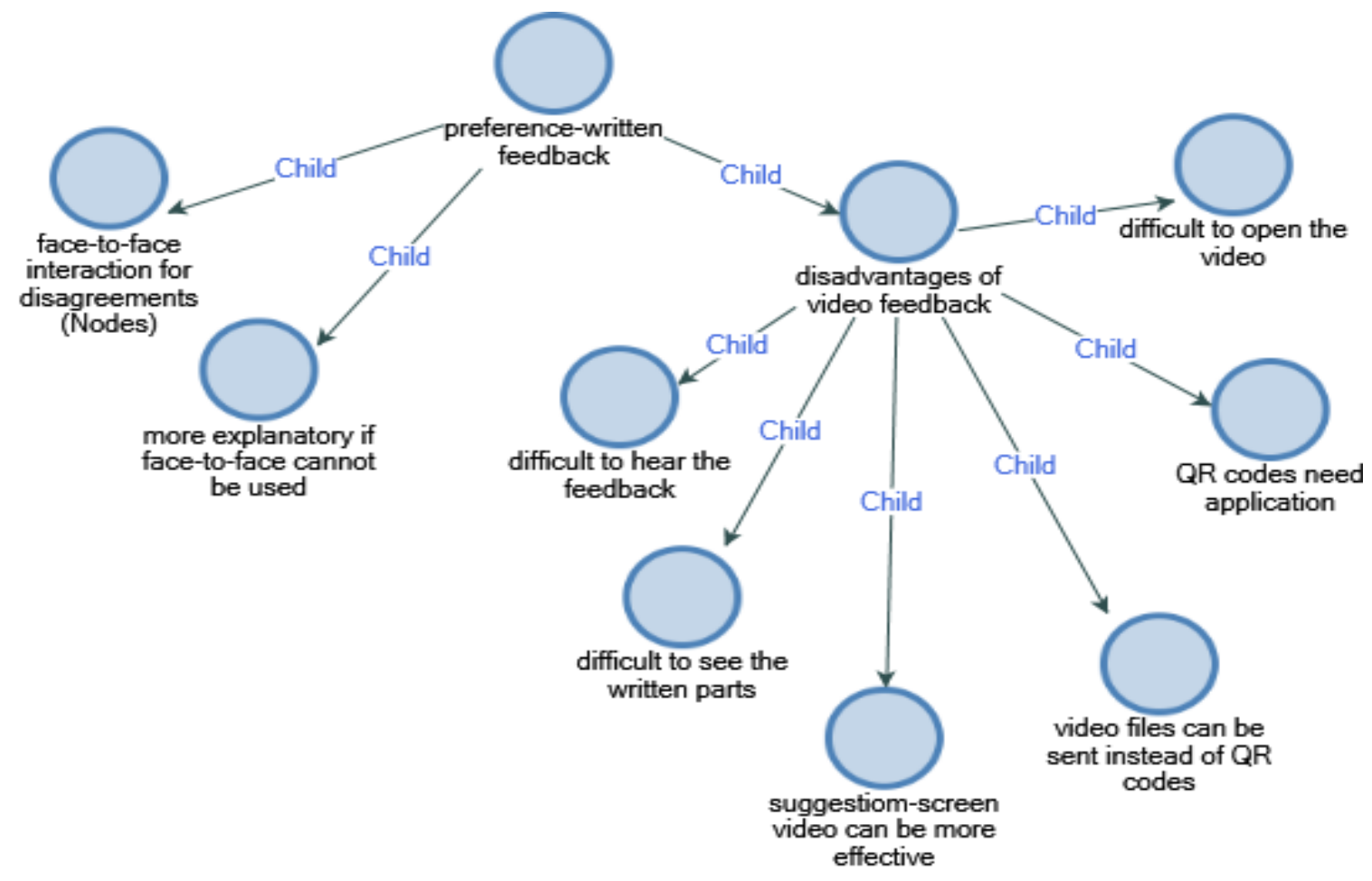

Fig.4: Reasons for Preferring written-only feedback

There are mainly two advantages stated by the preservice teachers. First, they found written-only feedback time-saving because they might get in contact with the instructor only when disagreements about the feedback occurred. Thus, instead of watching the whole video, they could focus only on the points which were not understood. This finding is also in line with the study of Borup et al. (2015) and Orlando (2016) where the students also preferred written feedback to video feedback because written feedback was easier to access and faster to skim through the comments.

The participants stated that they could get in touch with their instructors in case the feedback had some confusing points; however, they missed the point that during the pandemic, they were not able to meet their instructors face-to-face. Stating such a reason may show that the participants were used to the traditional procedure for receiving feedback and they felt safer that way during the pandemic too. This may imply that the participants could not adapt to the new methods in receiving feedback and might feel safer with the traditional procedure. During the interview, participant 8 stated:

[...] I would prefer written feedback. I feel safe that way...I do not like using technology that much...codes....videos. Learning should be simple.

Another advantage they stated was the benefit of a more detailed explanation they could receive with the written feedback. The feedback provided to the participants was more detailed in video feedback because the instructor explained the margin notes, commented on the video and suggested ways to improve the text. It may seem surprising that the written-only feedback was found more detailed. There may be two reasons for this finding. First, perhaps the participants did not watch the video feedback, and second, perhaps it was difficult to comprehend the feedback as stated in the second part of Figure 4. Thus, the margin notes and comments may seem more detailed to them. The learners may be visual learners and maybe they felt more comfortable with written-only feedback. 
While coding the themes, it was found that the participants who prefer written-only feedback over videofeedback+written feedback, made their choices because of the disadvantaged experiences they had with the video feedback+written feedback. As seen in Figure 4, the participants had difficulty in hearing the video feedback and seeing the written parts (meaning the notes, corrections and comments). Also, they experienced problems with the QR codes. For example, they had difficulty in opening the video with the code, they needed an application for scanning the code and perhaps their mobile did not have the size for that. Participant 13 supported his opinion during the interview with these lines:

[...]uhmm well, I liked to watch the video. I could also follow the feedback from the Word file....but it takes long time to receive the feedback. Uhmm .... I mean ... just the Word file is enough. For the video, I need the QR code application, a bigger screen.... and finding these takes time.

Participant 19:

[...]The Internet connection was weak on my phone...I could not download the video so it was difficult to watch... Written feedback was easier to access.

Because of these difficulties they experienced, the participants also made suggestions. They suggested screen video usage and video files to be sent via email. However, the problem with sending the video files via email was the size of the files causing difficulty in sending them.

As stated by the participants, they preferred written-only feedback mostly because of the technical difficulties they experienced with the procedure rather than the effectiveness of the written-only feedback type. Since they were away and in their hometowns during the pandemic, some of the participants did not have a computer or strong internet connections, so they usually used their mobile phones for working on the feedback they received. This may have been also a challenge for the participants.

\section{Reasons for Preferring Video feedback+Written feedback}

The participants were provided with video feedback and written feedback for their argumentation essays. They could reach their video feedback via a QR code. After scanning the code, they could watch their feedback on their screens. When the participants were asked about the reasons for preferring video+written feedback, they stated that they found video feedback more detailed and effective (Figure 5). They stated that video feedback was more detailed because the instructor had to explain the comments and suggestions made on the written feedback file in more detail. In other words, the instructor elaborated the written feedback. Also, they added that seeing their paper during the video made the confusing points clearer. Seeing-listening-reading helped them to comprehend the points to be improved in their essays more easily. Since they did not have the opportunity to have oral feedback sessions, video feedback was the closest to it to be used. This finding supports the literature about video feedback since it has put forward that video feedback provides the opportunity to receive more feedback and more detailed (Borup et. al., 2015; Crook et al., 2012; Elola \& Oskoz, 2016; Henderson \& Phillips, 2015; Lamey, 2015). Instead of focusing on corrective feedback like in written feedback, during video feedback, the instructor provided more feedback on global level of the essay. Thus, s/he explained the current situation in more detail.

Additionally, the way video feedback was used by the instructor was found effective. Both the video feedback and the way it was delivered to the participants, namely the QR codes, were satisfying for the participants. One of the participants even stated that the QR codes became a tool for her to increase her curiosity about the feedback and the learning process. 
Participant1:

[...]...I liked the video. I could get more detail actually...it was fun to receive feedback with QR code... it created curiosity...

Thus, the participants found video feedback so effective that they suggested receiving more video feedback during the term not only for one essay.

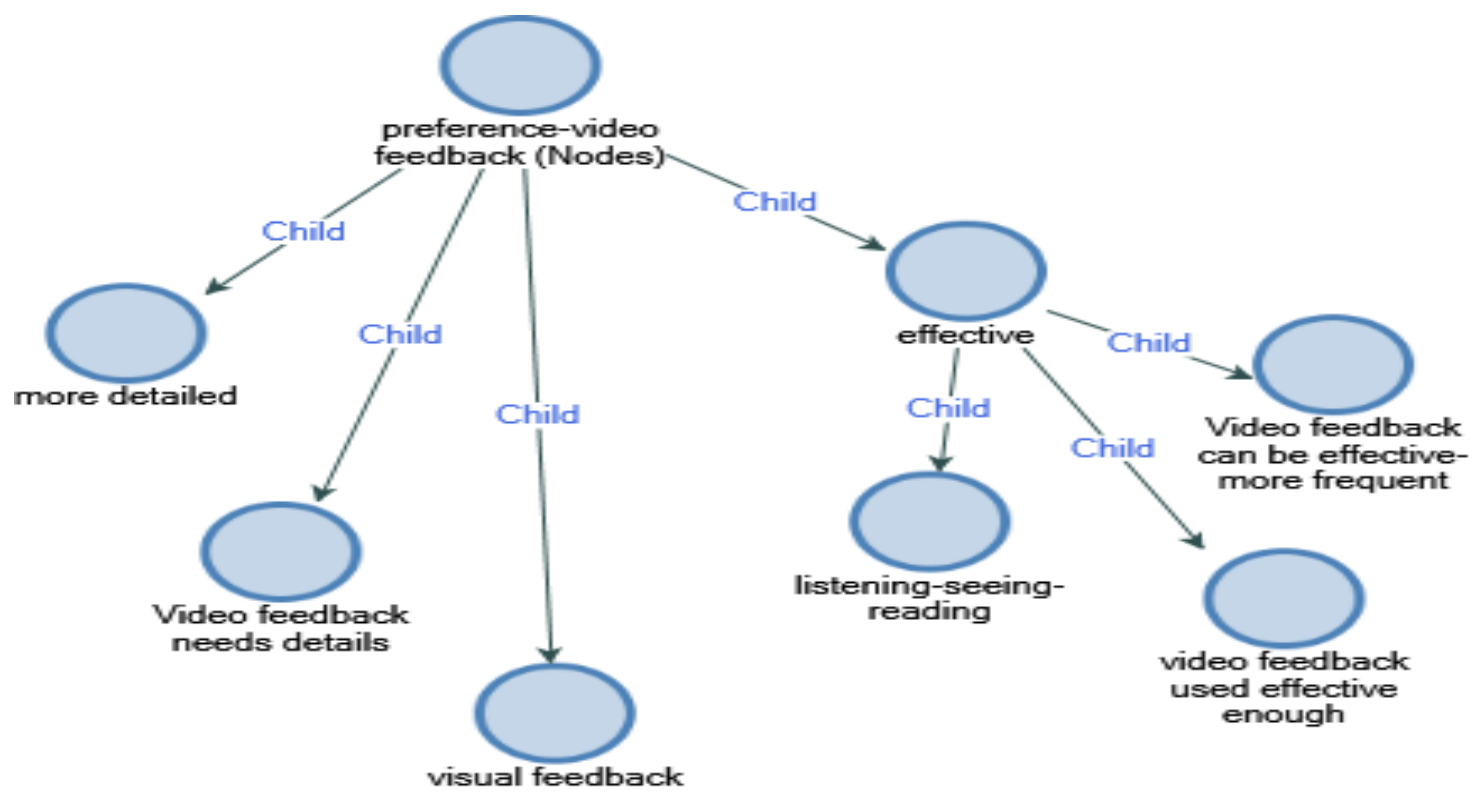

Fig.5: Reasons for preferring video feedback

In contrast to the reasons the participants stated for their written-only feedback, the participants who prefer video feedback+written feedback stated more details about their choice (Figure 6). First of all, the participants found video feedback beneficial for their final exam where they were also asked to write an essay. They could see their mistakes and understand how to correct them. This may be the reason why the participants found video feedback more detailed. They claimed that video feedback helped them improve their essay writing skills. However, they would like to receive more feedback on mechanical issues in the video feedback in addition to the feedback on the content and organization of their essays. The instructor focused more on global issues rather than mechanics and language use. This finding is also in line with previous studies (Anson et al., 2016; Borup et al., 2014; Elola \& Oskoz, 2016; Henderson \& Phillips, 2015).

The participants were also satisfied with video feedback because they received feedback on what they did better and were motivated to learn more. In addition, video feedback supported a way for building interaction with the learners during the pandemic and as Chen (2019) suggests interaction with the instructor may motivate the learner. This is also a finding in line with the study of Lamey (2015). Perhaps, the reason why instructors focus more on the positive aspects of the product of the learner can be the feeling of having an interaction with the learner via the recording. Psychologically, the instructors feel the need to greet the learner, address with their names and focus on positive aspects too so that it seems like a real interaction (Anson et al, 2016). A possible explanation can be that video feedback may reduce the perceived distance between the learner and the instructor (Thomas et al., 2017). 


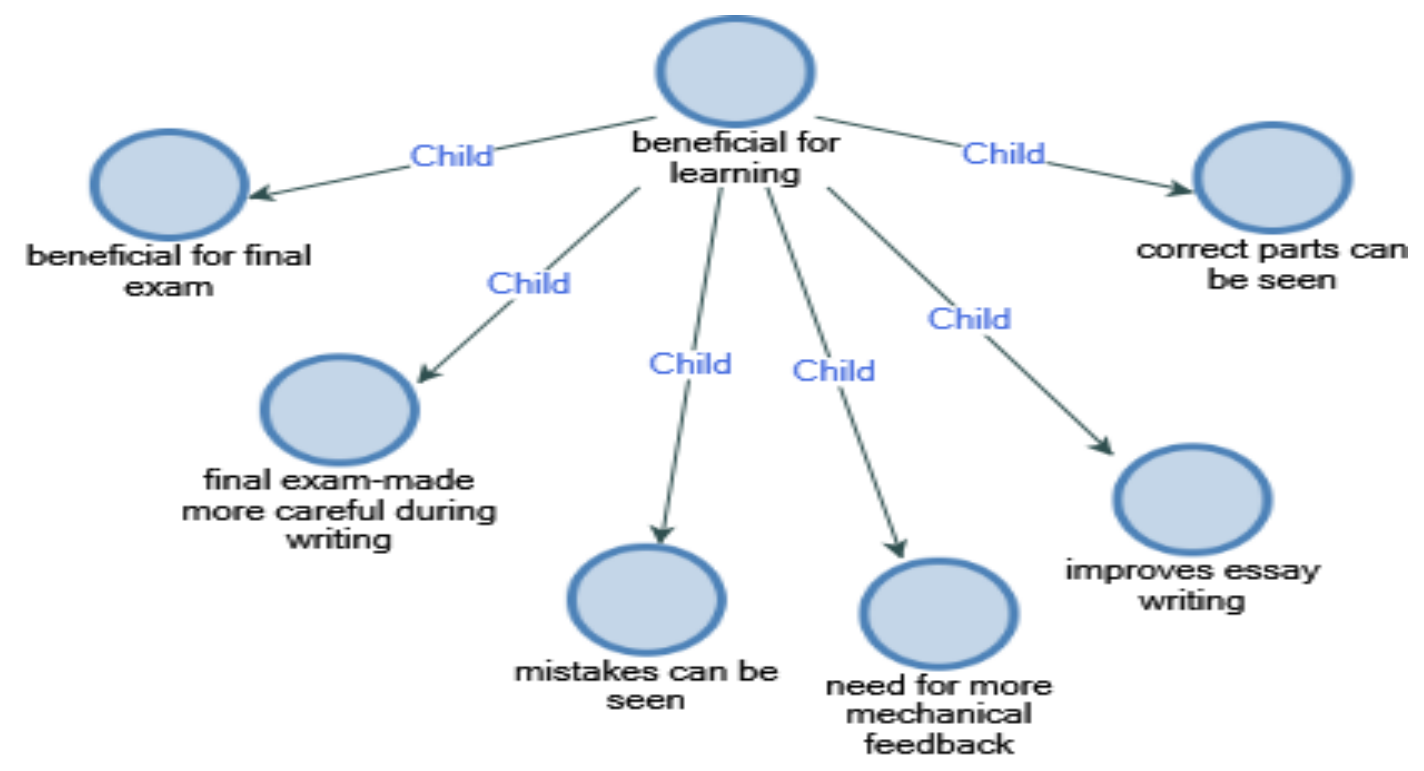

Fig.6: Opinions of participants on video feedback

Another point to be mentioned can be the feeling of being cared by the instructor. Participant 4 made the point that being cared during the pandemic made her feel safe and comfortable. Since they had no chance to meet the instructor face-to-face for receiving feedback, video feedback opened a new way to interact with the instructor about their essay.

\section{Participant 4:}

[...] Because of the pandemic, we couldn't receive live feedback...the video feedback was a little bit like live and like feeling safe and kind of cared by the teacher..."

Since the learner can hear the voice of the instructor, and the instructor focuses on positive achievements and encourages the learner, the learner may feel safer and more cared with video feedback (Anson et al., 2016; Harper et al., 2012). This may explain the feeling of participant 4.

To sum up, most of the preservice ELT teachers preferred video feedback+written feedback rather than written-only feedback for their essays. Despite this choice, they might have thought that written feedback was more effective than video feedback. The technological requirements for video feedback via QR codes and technical problems, such as poor Internet connection and the use of mobile phones for receiving the feedback made written-only feedback more preferable. Similarly, Agormedah et al. (2020) found in their study on online learning during the pandemic that learners feel satisfied using technology but have negative attitudes because of poor internet connection and not being trained for online learning. All the technical requirements for video feedback might have seemed like a waste of time for the participants. One reason for this situation may be the concerns the pandemic caused in terms of education. Moving to online education was a novel situation for both teachers and students. Also, the poor level of readiness of technology use for educational purposes can be another underlying reason for the findings of the study. 


\section{Discussions}

The study aims at finding out the experiences of ELT preservice teachers on video feedback which they received via QR codes for their essays. The participants were required to write two essays during the term for their Writing Skills course. Different from the aforementioned studies, this phenomenological study focused on the views of ELT pre-service teachers and the reported results revealed that most of the participants prefer written feedback+video feedback for their essays. Consequently, the contribution of using video feedback and written feedback with teacher candidates was two-fold; (1) the ELT preservice teachers could develop their academic writing skills, and (2) they had the opportunity to learn how to provide feedback for their future learners.

The ELT preservice teachers were found more encouraged for writing when they received written and video feedback from their instructors. The reasons for this phenomenon can be inferred as the inborn need for being cared. These findings echo what Borup et al. $(2014 ;$ p.249) stated on video feedback. According to the researchers, video feedback can be regarded as a beneficial means for establishing "social presence" because social presence is less achieved in blended courses where learning is face-to-face, so it cannot be wrong to state that for online courses social presence is a significant issue too. In other words, Belt and Lowenthal (2021) state that video feedback can be considered as a tool in terms of the social constructivist theory because video feedback can be seen as a prospect for establishing social presence and a form of affective relationships between the learners and instructors (see also Draus et al., 2014). The participants of the study in question stated that video feedback was a sign for them that their instructor cared about them, especially during the sudden lockdown. Unanticipatedly, they had to switch from face-to-face to online education where they felt especially frustrated for their academic lives. They were aware that their instructor spent effort on the individualized feedback which may have helped them feel less frustrated.

Video feedback presents advantages for the learners as it provides the learners with more detailed feedback (Mayhew, 2017; Vincelette \& Bostic, 2013; Moore \& Filling, 2012), the instructor's voice, and intonation. It can be seen as a tool for establishing social presence for both face-to-face and online courses since the instructor starts the video by greeting the learner by name, praises (Lamey, 2015; Thomas et. al., 2017) the achieved tasks first and connects to the learners socially (Anson et al., 2016; Grigoryan, 2017). The findings of the current study are in line with the literature. Most of the participants preferred written+video feedback for their essays because they thought they received more detailed feedback especially on the global level of their work. During the video feedback, since the participants heard the instructor talking, it was like a conversation so they did not feel isolated. Thus, the subjects reported that they found video feedback the closest to oral feedback they had been receiving before the lockdown. The participants found video feedback so effective that they stated they wished that they had received more video feedback for their previous work, too. However, they highlighted that they would like to have been provided with more feedback on mechanical issues during the video feedback sessions, this finding is also in line with the literature (Anson et al.,2016; Borup et al.,2014; Elola \& Oskoaz, 2016; Henderson \& Phillips,2015).

Motivation was reported as another reason for choosing video feedback. The underlying reason may be the positive language that the instructor used during the video. The instructor greeted the learners, addressed them with their names, and started giving feedback by focusing on the positive sides of their work (Anson et al., 2016). Social interaction has a key role in motivation and the study of Meşe and Sevilen (2020) supports this (also see Chen, 2019). As a result, video feedback may reduce the perceived distance between the learner and the instructor (Thomas et al., 2017), and in return, the motivation to develop better texts can come to an existence (Garrison, 2009; Li et al., 2020; Thoms, 2011).

Despite the advantages video feedback+written feedback presents for the learners in the study at issue, the participants found written-only feedback more effective for the development of their writing skills. In other words, this finding can be considered to be contradictory because, as stated before, while most of the participants preferred written+video feedback, they found written-only feedback more effective (Borup et 
al., 2015; Li et al., 2020). The reason for this alleged contradiction may be the efficient nature of the text (Li et al., 2020) since written feedback can be an opportunity for the learners "to read, process, relate and link the feedback to their performance at their own pace" (p.502). While reading the feedback, the learner has the opportunity to skim for keywords, but for video feedback, they should take notes about the key points (Borup et al., 2015; Orlando, 2016). This process may make video feedback disadvantageous because learners need to spend more time figuring out the feedback provided. In addition, written feedback is easier to access compared to video feedback (Orlando, 2016). Another possible reason for this finding can be that mentally the students could not switch to online learning from traditional learning. They felt safer with written feedback because this was what they were used to (see the extract from participant 8). In addition, students' inefficient use of the technology was another aspect considered to have a key role on this contradiction about the ineffectiveness of video feedback. Although most of the participants found video feedback beneficial, some of them reported that they had experienced problems with the technology which led them to choose written-only feedback unavoidably. They explained this by stating that they were not good at using technological devices, watching the video feedback from mobiles was troublesome, and it was time-consuming for them to download a QR scanning application and watch the video. Written-only feedback was regarded to be more straightforward by them. The participants in the current study found video feedback beneficial but had concerns related to technology since they could not make the QR application work, even if they had, they experienced trouble in playing the video; therefore, they could not receive proper feedback for their work. In other words, it can be stated that learners prefer to use technology but because of the negative factors affecting it, so they would rather be taught without technology. This finding is also supported by the literature (Agormedah et al., 2020; Li et al., 2020). These might have led the learners to experience bigger and more psychological drawbacks of using technology which can be stated as frustration and distraction. These feelings and video feedback's being time-consuming may have caused the learners to create negative feelings towards writing and the course. However, these are problems that can be solved. To illustrate, the learners will download a QR scanning application just once, or the feedback can be shared on drive/cloud systems. When the fact that these participants are the teachers of the future is considered, providing them with video feedback should be regarded as a valuable tool since it will also prepare them for the classrooms of the digital generation.

\section{Implications of the study}

This qualitative study focused on written+video feedback and written-only feedback for ELT preservice teachers. Thus, the two-sided implications of the study both had been expected by the researcher and were considered as valuable resources for clarifying the phenomenon at issue.

In terms of the learning perspective, written+video feedback can be regarded as advantageous for the language learner since it provides detailed feedback on both local and global issues, establishes social presence, and supports affective factors (such as being cared etc.) in learning. Although the study, like the other studies which had been done so far in the relevant literature, may not support that one way of feedback is superior to the other one, this study reveals that what matters is the learner and his/her preferences. The learners may be asked to make a preference about the medium of feedback before the instructor gives feedback. Besides their preference, the instructor may choose to switch from one type of feedback to another for different reasons. S/he may favor using video feedback at the beginning of the course to show the learner how to interpret the given feedback, show affection, and construct a relationship with the learner; then, s/he may continue with written feedback depending on the needs and expectations of the learners ( $\mathrm{Li}$ et al., 2020; Palloff \& Pratt 2007). In addition, video feedback can be used to boost the motivation of the learners in their process of developing their writing skills. In other words, the feeling of being cared and given importance can trigger the motivation of the learners (Garrison, 2009; Li et al., 2020; Thoms, 2011). Another implication of the study is training students on using technology before starting using it for 
teaching and learning. Thus, learners' readiness can be supported via teacher instructions (Agormedah et al., 2020). This can be solution for the complaints on using the QR codes, perhaps.

From the teaching perspective, written+video feedback shows ELT preservice teachers that written feedback is not their only choice but they have other and much more up-to-date alternatives, such as the video format. While interpreting the feedback they receive, the students also learn how to provide feedback for their future learners and the tools/ways which help them facilitate the process. This makes a reference to Putnam and Borko (2000) who state that teacher candidates need feedback from their instructors to get one step further in the teaching profession. Consequently, by providing feedback to learners via text, audio and video tools, the instructor gets the opportunity to show the teacher candidates that providing feedback is significant and they may develop technological skills regarding teaching with technology (Nillas 2008).

\section{Limitations}

Although this study presented insightful findings for educators, it was limited to the study context. First, the findings were related to ELT preservice teachers and a writing course. Using QR codes for video cannot be mentioned as a limitation but it is worth mentioning that there are other ways to deliver the video feedback to learners, such as uploading the files to drive/cloud systems. This could prevent the complaints about downloading QR scanning applications mentioned by the participants. Some participants complained about their weak Internet connection. This can be regarded as one of the limitations of the study.

\section{Conclusion and Suggestions}

The aim of this study is to find out the opinions and experiences of preservice ELT teachers on video feedback for their writing skills course. Based on this aim, during the spring term, the participants were provided two types of feedback for their essays: written-only and video feedback+written feedback. At the end of the term, the participants were asked to complete a survey about their experiences, and eight of the participants were interviewed for further information. Considering the design of the study, phenomenological study design was applied to shed light on the use of video feedback in writing skills courses with preservice ELT teachers.

The study revealed that while the preservice teachers prefer video feedback for their essays, they found written-only feedback more effective. The preference for video feedback was the result of more detailed comments, more elaboration, and seeing-listening-reading opportunities. Additionally, video feedback made them feel more cared and motivated for improving their writing, this was found precious because of the difficult conditions experienced during the first lockdown of the pandemic. On the other hand, they were more written-only effective because it was time-saving, no application was required (referring to the QR code scanning application), less technology was demanded for written-only feedback.

Considering, the findings of the study, video feedback can be recommended for teaching academic writing in English because it was found more detailed and made the preservice teachers more motivated for the course. However, video feedback can be demanding for the instructor so further studies could be conducted to find out the experiences of the instructors providing video feedback. Technological readiness was another issue that was found in the study. The participants did not feel ready for using QR codes, videos and etc. at the beginning of the pandemic. Another study can compare their readiness level for technology use and the effect of video feedback on essay development of ELT preservice teachers. Since the participants had difficulty in scanning the QR codes, cloud or drive applications may be used to share the video files. Another enlightening suggested study may focus on the effect of written-only and video feedback on essay development preservice teachers by comparing the revised versions of their essays based on an evaluation criterion. 


\section{References}

Ahern-Dodson, J. \& Reisinger, D. (2017). Moving beyond corrective feedback: (Re) Engaging with student writing in L2 through audio response. Journal of Response to Writing, 3(1), 129-152.

Agormedah, E. K., Adu Henaku, E., Ayite, D. M. K., \& Apori Ansah, E. (2020). Online learning in higher education during COVID-19 pandemic: A case of Ghana. Journal of Educational Technology \& Online Learning, 3(3), 183-210.

Ajjawi, R., \& Boud. D. (2018). Examining the Nature and Effects of Feedback Dialogue. Assessment and Evaluation in Higher Education, 43(7), 1106-1119. doi:10.1080/02602938.2018.1434128.

Anson, C. M., Dannels, D. P., Laboy, J. I., \& Carneirn, L. (2016). Students' Perceptions of Oral Screencast Responses to Their Writing: Exploring Digitally Mediated Identities. Journal of Business and Technical Communication, 30(3),378-411.

Atwater, C., Borup, J., Baker, R., \& West, R. E. (2017). Student perceptions of video communication in an online sport and recreation studies graduate course. Sport Management Education Journal, 11(1), $3-12$.

Belt, E.S. \& Lowenthal, P. R. (2021). Video use in online and blended courses: a qualitative synthesis. Distance Education, 42(3), 410-440.

Borup, J., West, R. E., Thomas, R., \& Graham, C. R. (2014). Examining the impact of video feedback on instructor social presence in blended courses. The International Review of Research in Open and Distance Learning, 15(3), 232-256.

Borup, J., West, R. E., \& Thomas, R. (2015). The impact of text versus video communication on instructor feedback in blended courses. Educational Technology Research and Development, 63(2), 161-184.

Boud, D., \& E. Molloy (2013). Rethinking Models of Feedback for Learning: The Challenge of Design. Assessment and Evaluation in Higher Education, 38 (6), 698-712.

Bitchener J., \& Knoch U. (2009). The relative effectiveness of different types of direct written corrective feedback. System, 37, 322-329.

Bonilla López M., Van Steendam E., Speelman D., \& Buyse K. (2018). The differential effects of comprehensive feedback forms in the second language writing class. Language Learning, 68, 813850 .

Borup, J., West, R. E., \& Thomas, R. (2015). The Impact of Text Versus Video Communication on Instructor Feedback in Blended Courses. Educational Technology Research and Development, 63(2), 161-184.

Cavanaugh, A. J., \& Song, L. (2014). Audio feedback versus written feedback: Instructors' and students' perspectives. MERLOT Journal of Online Learning and Teaching, 10(1), 122- 138.

Chen, C. (2019). A comparative study of online teacher-involved and peer interactive learning: Chinese EFL students' perceptions and practices. Journal of Educational Technology \& Online Learning, 2(1), 56-73.

Creswell, J. W. (2005). Educational Research: Planning, conducting, and evaluating quantitative and qualitative research ( $2^{\text {nd }}$ edition). Pearson, Merrill Prentice Hall.

Crook, A. C., Park, J. R., Lawson, C. S., Lundqvist, K. O., Drinkwater, R., Walsh, J., Gomez, S., Orsmond, P., \& Maw. S. J. (2010). ASSET: Moving Forward Through Feedback (Final Report). Reading: University of Reading. $\quad$ ASSET website,http://www.reading.ac.uk/web/FILES/asset/ASSET_final_report.pdf. 
Draus, P. J., Curran, M. J., \& Trempus, M. S. (2014). The influence of instructor-generated video content on student satisfaction with and engagement in asynchronous online classes. Journal of Online Learning and Teaching, 10(2), 240-254.

Donkin, R., Askew, E., \& Stevenson, H. (2019). Video feedback and e-learning enhances laboratory skills and engagement in medical laboratory science students. BMC Medical Education, 19(1), 1-12

Dowden, T., Pittaway, S., Yost, H., \& McCarthy, R. (2013). Students' Perceptions of Written Feedback in Teacher Education: Ideally Feedback is a Continuing Two-Way Communication That Encourages Progress. Assessment and Evaluation in Higher Education, 38(3), 349-362.

Ellis, R. (2006). Implicit and explicit corrective feedback on the acquisition of L2 grammar. SSLA, 28(2), 339-368.

Elola, I., \& Oskoz, A. 2016. Supporting Second Language Writing Using Multimodal Feedback. Foreign Language Annals, 49 (1), 58-74.

Ferris, D. R. (2002). Treatment of error in second language student writing. Ann Arbor: University of Michigan Press.

Ferris, D. R. \& Roberts, B. (2001). Error feedback in L2 writing classes: How explicit does it need to be? Journal of Second Language Writing, 10(3), 161-184.

Garrison, D. R. (2009). Implications of online learning for the conceptual development and practice of distance education. Journal of Distance Education, 23(2), 93-104.

Goldingay, S., \& Land, C. (2014). Emotion: The "e" in engagement in online distance education in social work. Journal of Open, Flexible \& Distance Learning, 18(1), 58-69.

Grigoryan, A. (2017). Audiovisual Commentary as a Way to Reduce Transactional Distance and Increase Teaching Presence in Online Writing Instruction: Student Perceptions and Preferences. Journal of Response to Writing, 3(1), 83-128.

Gould, J., \& Day, P. (2013). Hearing You Loud and Clear: Student Perspectives of Audio Feedback in Higher Education. Assessment and Evaluation in Higher Education, 38(5), 554-566.

Harper, F., H. Green \& Fernandez-Toro, M. (2012). Evaluating the Integration of Jing Screencasts in Feedback on Written Assignments. Paper presented at the 15th annual conference on interactive collaborative learning (ICL), Villach, Austria.

Henderson, M., \& Phillips, M. (2014). Technology Enhanced Feedback on Assessment. Paper presented at the Australian computers in education conference, Adelaide, Australia. http://acec2014.acce.edu.au/session/technology-enhanced-feedback-assessment.

Hyland, K. \& Hyland, F. (2006). Feedback on second language students' writing. Language Teaching, 39(2), 83-101.

Hyland, K. \& Hyland, F. (2019). Feedback in second language writing: Contexts and issues. Cambridge: Cambridge University Press.

Ice, P., Curtis, R., Phillips, P., \& Wells, J. (2007). Using asynchronous audio feedback to enhance teaching presence and students' sense of community. Journal of Asynchronous Learning Networks, 11(2), 325.

Jolly, B., \& Boud. D. (2013). Written feedback: What is it good for and how can we do it well? In D. Boud, and E. Molloy (eds). Feedback in Higher and Professional Education: Understanding It and Doing It Well,(pp.104-124). Abingdon: Routledge. 
Kormos, J. (2012). The role of individual differences in L2 writing. Journal of Second Language Writing, 21(4), 390-403.

Kostka, I. \& Maliborska, V. (2016). Using Turnitin to provide feedback on L2 writers' texts. The Electronic Journal for English as a Second Language, 20(2), 1-22.

Lamey, A. (2015). "Video Feedback in Philosophy.” Metaphilosophy, 46(5),691-702.

Li, J., Wong, S. C., Yang, X., \& Bell, A. (2020). Using feedback to promote student participation in online learning programs:evidence from a quasi-experimental study. Education Technological Research and Development, 68, 485-510.

Mahoney, P., Macfarlane, S. \& Ajjawi, R. (2019). A qualitative synthesis of video feedback in higher education. Teaching in Higher Education, 24(2), 157-179.

Mathisen, P. (2012). Video Feedback in Higher Education - A Contribution to Improving the Quality of Written Feedback. Nordic Journal of Digital Literacy, 7(2), 97-116.

Mayhew, E. (2017). Playback Feedback: The Impact of Screen-Captured Video Feedback on Student Satisfaction, Learning and Attainment. European Political Science, 16(2), 179-192.

Meşe, E. \&Sevilen, Ç. (2020). Factors influencing EFL students' motivation in online learning: A qualitative case study. Journal of Educational Technology \&Online Learning, 4(1), 11-22.

Moore, N. S., \& Filling, M. L. (2012). iFeedback: Using Video Technology for Improving Student Writing. Journal of College Literacy and Learning, 38, 3-14.

Nillas, L. A. (2008). Challenges in preparing preservice teachers to teach using technology. In K. McFerrin (Ed.), Society for information technology \& teacher education international conference. (pp.42564261). Chesapeake, VA: AACE.

Orlando, J. (2016). A Comparison of Text, Voice, and Screencasting Feedback to Online Students. American Journal of Distance Education, 30(3), 156-166.

Palloff, R. M., \& Pratt, K. (2007). Building online learning communities (2nd ed.). San Francisco: JosseyBass.

Ruegg, R. (2018). The effect of peer and teacher feedback on changes in EGL students' writing selfefficacy. The Language Learning Journal,46(2), 82-102.

Sheen, Y. \& Ellis, R. (2011). Corrective Feedback in Language Teaching. In E. Hinkel (Ed.). Handbook of Research in Second Language Teaching and Learning Volume II, (pp.593-610). New York: Routledge.

Thomas, R. A., West, R. E. \& Borup, J. (2017). An Analysis of Instructor Social Presence in Online Text and Asynchronous Video Feedback Comments. The Internet and Higher Education, 33, 61-73.

Thoms, B. (2011). A dynamic social feedback system to support learning and social interaction in higher education. IEEE Transactions on Learning Technologies, 4(4), 340-352.

Thompson, R., \& Lee. M. J. (2012). Talking with Students Through Screencasting: Experimentations with Video Feedback to Improve Student Learning. Journal of Interactive Technology, 1. https://jitp.commons.gc.cuny.edu/talking-with-students-through-screencasting-experimentationswith-video-feedback-to-improve-student-learning/.

Turner, W., \& West. J, (2013). Assessment for 'Digital First Language' Speakers: Online Video Assessment and Feedback in Higher Education. International Journal of Teaching and Learning in Higher Education, c25(3), 288-296. 
Truscott, J. (1996). The case against grammar correction in L2 writing classes. Language Learning, 46(2), 327-369.

Van Beuningen C., De Jong N. H., \& Kuiken F. (2012). Evidence on the effectiveness of comprehensive error correction in second language writing. Language Learning, 62(1), 1-41.

Vardi, I. (2013). Effectively Feeding Forward from One Written Assessment Task to the Next. Assessment and Evaluation in Higher Education, 38(5), 599-610.

Vincelette, E. J., \& Bostic, J. (2013). Show and Tell: Student and Instructor Perceptions of Screencast Assessment. Assessing Writing, 18(4), 257-277.

Waller, L. \& Papi, M. (2017). Motivation and feedback: How implicit theories of intelligence predict L2 writers' motivation and feedback orientation. Journal of Second Language Writing, 35, 54-65.

Wood, K. A., Moskovitz, C., \& Valiga, T. M. (2011). Audio feedback for student writing in online nursing courses: Exploring student and instructor reactions. Journal of Nursing Education, 50(9), 540-543.

Wright, K. L., Hodges, T. S., \& McTigue, E. M. (2019). A validation program for the Self-Beliefs, WritingBeliefs and Attitude Survey: A measure of adolescents' motivation toward writing. Assessing Writing, 39, 64-78.

Yu, S., Wang, B., Teo, T. (2018). Understanding linguistic, individual and contextual factors in oral feedback research: a review of empirical studies in L2 classrooms. Educational Research Review, 24, 181-192.

Yuan, J., \& Kim, C. (2014). Guidelines for facilitating the development of learning communities in online courses. Journal of Computer Assisted Learning, 30(3), 220-232. 